\title{
Detecting Research Trends in Korean Information Science Research, 2000-2011*
}

\author{
국내 정보학분야 연구동향 분석, 2000-2011 \\ Eun-Gyoung $\mathrm{Seo}$ (서은경)** \\ So-Young Yu (유소영)***
}

\begin{abstract}
Even though the overall scholarly community has recognized a dramatic growth and changes in the Information Science research in Korea over the last few decades, there are still only few studies that have identified the changes in terms of long-term and dynamic point of view. We have analyzed 1,007 IS-research articles from leading Korean journals in KCI (Korea Citation Index), published between 2000 and 2011. To discern the trendline of changes in research interests over time, we conducted a time-series analysis by developing grounded subject scheme from the article set and checking the growth rate of the number of published articles and title keywords. A comparative analysis was also conducted by constructing and comparing co-word maps over time to discover visible changes in research topics over this 12-year period of the IS-research in Korea. As a result, we identified some developments and transformations in major subject areas and knowledge structure of the IS-research in Korea over time. The major trend we discovered is that IS-studies over the 12-year period evolved from system-oriented research to library-application research. The changes are especially observed in knowledge management, Web-based system evaluation, and information retrieval areas. When compared to the results of other studies, the result of our study may serve as an evidence of the localization of Korean IS-studies in the first decade of the $21^{\text {st }}$ century.
\end{abstract}

\section{초 록}

21세기에 들어서서 디지털 정보환경이 발빠르게 변화함에 따라 국내 정보학 연구 역시 많은 발전과 변화를 겪고 있는 것을 산학계 모두 인지하고 있지만 실제 2000년부터 현재까지 어느 정도로 변화되었는지를 분석한 논문은 많지 않다. 이에 따라 본 연구는 2000년에서부터 2011기간동안 연구재단에 등재된 문헌정보학 관련 학회지에 수록된 정보학분 야 논문 1,007 편의 논문을 대상으로 정보학분야의 연구동향을 분석하였다. 먼저 시간에 따른 연구주제의 변화를 살펴보기 위하여 논문 데이터를 주제 범주화 한 후, 각 주제 범주 내에서의 논문 및 주요 키워드의 성장률을 시계열적으로 분석하였다. 그리고 단어 동시출현 네트워크를 2000-2011년뿐 아니라 2000-2005년과 2006-2011년의 두 시기로 나누어 시각화하고 분석함으로써, 한국의 정보학 분야의 연구경향의 변화를 살펴보았다. 분석 결과, 지난 12 년간의 한국의 정보학 연구는 정보시스템중심적 연구에서 이를 도서관에 적용하는 도서관응용적 연구로 나아가고 있는 것을 확인하였다. 특히 지식관리, 웹기반 시스템 평가, 정보검색 분야에서 두드러지게 변화가 나타났다. 다른 연구의 결과와 비교해 볼 때, 이 연구는 정보학 연구분야의 한국 로컬화의 변화를 찾아냈다는 점에서 의의가 있다고 할 수 있다.

Keywords: research trends analysis, co-word analysis, information science, time-series analysis, Korea 연구동향분석, 단어 동시출현 분석, 정보학, 한국, 시계열분석

* This research was supported by Hansung University.

** Professor, Division of Knowledge \& Information at Hansung University

(egseo@hansung.ac.kr) (First author)

*** Assistant Professor, Dept. of Library \& Information Science at Hannam University

(soyoungyu201@gmail.com) (Corresponding author)

- 논문접수일자 : 2013년 11월 27일 - 최초심사일자 : 2013년 12월 5일 - 게재확정일자 : 2013년 12월 13일

- 정보관리학회지, 30(4), 215-239, 2013. 〔http://dx.doi.org/10.3743/KOSIM.2013.30.4.215〕 


\section{Introduction}

Information Science (IS) is not exactly new boasting a 60 year history. Also, the scope of IS includes a wide range of disciplines and technologies that depend on and work with information resources of all types (Seadle, 2012). Research and development activities in science and technology and other fields of human endeavor have contributed significantly to the phenomenal growth in research themes. In recent years, the changes in information technology have been dramatic, and the amount of technology integration in the information environment has increased so much that IS research has been rigorously evolving with the passage of time and dynamically proliferating in diverging research directions.

IS researches in Korea have been proliferating since the foundation of Journal of the Korean Society for Information Management in 1984. According to the researches that examined the Information Science research patterns in Korea in the 1990s, Korean researches shifted from library system-related studies to information processing-related studies and IS research in Korea has been focusing on new emergent issues (Seo, 1997; Sohn, 2003; Oh \& Lee, 2005). Since 2000, there have been many changes in the Korean IS landscape because new areas of study have emerged and the education programs have been changed. In Korea, the systematic research in the IS field had been conducted in the last quarter of the twentieth century, but it was in the 21st century that the amount of research began to grow rapidly (Seo, 2010a). Seo (2010b) examined also the topics of research articles published in Journal of Korean Society of Information Management between 1984 and 2009, dividing this time into three 'publication windows': 1984-1994, 1995-2002, 2003-2009. It was found that the most productive areas were 'Information Service', followed by 'Information Organization' and 'Information System', while the most productive sub-areas were 'Library Service', 'User Study', 'Automatic Document Analysis', 'Integrated Library System', 'Thesaurus/Ontology', and 'Digital Library.' As a result of comparing three intellectual structures of title keywords, the main area in the IS field was 'Information Retrieval', and the research on IT application and system evaluation have been expanded gradually. The findings are along with the other research which identified the localized research domain in Korean information science studies, such as digital library or user behavior (Cho, 2011; Kim \& Lee, 2007; Park \& Song, 2013).

It is obvious that there have been changes in IS over time and that the relative focus of IS research has been changing continuously with some topics being researched more and more intensively, some being studied constantly, while others disappearing. Tracking the changes in IS research leads to a better understanding of the current state, enables identification of other paths that diverged from the one that led directly to today's IS, and it may also predict future events. However, there are only few studies that attempted to identify the changes in research trends over a long period of time because of the immense difficulties caused by the blurred boundary among research themes and changes within them. 
The purpose of this study is to analyze the themes of Korean IS research and trace its changes in the 2000-2011 periods. The study intention is to conduct a diachronic analysis of the data wherever possible. Rather than taking a single snapshot of the scene observable at a given point in time, the aim is to present a series of such pictures, so that they may be compared and trends identified over time. The underlying questions focus on the following: 1) thematic characteristics of the IS field in Korea; 2) changes in Korean IS research from 2000 to 2011; 3) sharply increasing and sharply decreasing areas of research; 4) changes in the prominence of topics and 5) evolvement of major research domains over time. It is important for scholars and practitioners to know where the discipline has been and where it is going because it helps them understand knowledge of fundamental bases and emergent issues in their discipline. It is also valuable to identify knowledge networks to understand the domain of Information Science. Therefore, delineating the nature of information science research in Korea and tracing its research trends are ways of understanding and grasping the knowledge of information science.

\section{Literature Review}

Since the 1990s, when the IS began flourishing in its own right and on a large scale, and when its history was also long enough to be analyzed and reflected upon, several researchers such as White and McCain (1998), Hawkins (2001), Zins (2007), and
Robinson (2008) have attempted to chart the IS boundaries. Hawkins (2001) listed 12 major IS subject areas, such as properties of information, information access, information industry, knowledge organization, publishing, information marketing economics, database production, electronic information systems, online searching, current awareness, database design, and history. Zins (2007) classified the IS research areas into two major categories: meta-knowledge and subject-based knowledge with 10 basic sub-categories, such as foundations, resources, knowledge workers, contents, applications, operations and processes, technologies, environments, organizations, and users. As expected, the 12 major IS subject areas which Hawkins listed in 2001 somewhat differ from those 10 areas which Zins suggested in 2007. Compared with these two subject taxonomy schemes, Hawkins' subject areas such as 'database production', 'online searching', 'current awareness', and 'database design' merged into 'operations and processes' in the Zins' scheme, while new subject areas such as 'knowledge worker' and 'environments' appeared in the Zins' scheme. It is obvious that in the decade of explosive development of the WWW, IS areas changed, driving the creation of new areas and either revitalization or obsolescence of the old ones.

Recently, trends analysis researches in the field of information science have been carried out by observing changes in the main research topics over time, or by drawing intellectual structures. Zhao \& Strotmann (2008) employed an enriched author bibliographic coupling analysis and author co-citation analysis methodology for a comparison between the 
structure of intellectual influences on IS research during the first decade of the Web (1996-2005). They discovered that the Web has had a truly profound effect on the intellectual structure of IS, spawning new research areas such as Webometrics, while outdating other previously strong areas such as OPACs and online retrieval. In the same time period, they also discovered a major trend pertaining to the increasing prominence of the cognitive approach research areas in the IS field. Such approach accelerated to the degree that the corresponding research areas have surpassed all others in prominence. In an effort to distinguish the shift in top keywords occurrences, Chua \& Yang (2008) analyzed keywords of all research articles published in the Journal of American Society for Information Science and Technology (JASIST) and compared the articles between two 10-year periods, namely, 1988-1997 and 1998-2007. They found out that amid heterogeneous clusters of collaboration among top authors, strongly connected cross-disciplinary coauthor pairs became more prevalent, and correspondingly the distribution of top keywords that lean heavily on core IS domain has shifted towards other sub-disciplines, such as information technology and socio-behavioral science.

Huang \& Chang (2011) investigated the interdisciplinary changes in the IS field in the 1978-2007 period by analyzing five information science journals. They especially examined the annual changes in the number of disciplines in reference sources and in the interdisciplinary value of IS based on direct citation analysis. As a result, they found that the degree of interdisciplinary research in the IS field has been increasing over time, while co-authorship from the discipline of computer science has been decreasing. They also found out that IS researchers tend to cite more publications from outside the discipline of LIS and write collaborative papers with researchers from diverse disciplines. In particular, the growing trend in co-authorship is more obvious than in cited publications. Rorissa and Yuan (2012) draw the intellectual landscape of information retrieval, which is a long established subfield of Information Science, through visualizations of citation behaviors. Citation data for 10 years (2000-2009) were retrieved from the Web of Science and analyzed using existing visualization techniques. They concluded that the top five disciplines that contribute to information retrieval were computer science, library and information science, engineering, telecommunications, and management. They concluded that the information retrieval subfield's body of literature is expanding into areas not extensively covered in the years prior to 2000 . A quantitative investigation of information science publications indexed in Web of Science by scholars affiliated with Canadian institutions was conducted for the period 1989 to 2009 as follow-up a 1991 study conducted by Chu and Wolfram (Chu, \& Wolfram, 1991; Wolfram, 2012). The findings reveal essentially linear growth in the contributions, as institutions housing library and information science programs contribute the most publications. The largest growth was observed in the area of information behavior, where greater levels of author and inter-institutional co-authorship have been observed in recent years. 
Most researchers noted that the stable structures of IS areas are IR, information seeking and informetrics and there is the strong relationship between research topics and technological development. However, the focusing areas and the breadth of IS differ with countries.

\section{Methodology}

$<$ Figure $1>$ shows the methodological process of the study. After collecting data and categorizing the dataset, time-series analysis was conducted by the number of author, articles, keywords and their growth rate over time. Comparative analysis was performed by extracting and visualizing co-word maps over time and detecting the changes in major research domains in the maps.

\subsection{Data Collection}

This paper presents a time-series analysis and structural comparison of co-word networks in the Korean information science research. The first phase of the investigation was to choose the leading academic Korean LIS journals which include IS research articles. All scholarly journals which are published by Korean academic societies 1 ) in the field of LIS are, first, selected and then only journals which are accredited as academic journals by the National Research Foundation of Korea were selected and indexed by KCI (Korea Citation Index) were selected. Ultimately, four journals accredited as academic journals by the National Research Foundation of Korea were selected: 'Journal of the Korean Biblia Society for Library and Information Science (JKBSLIS)', 'Journal of Korean Library and Information Society

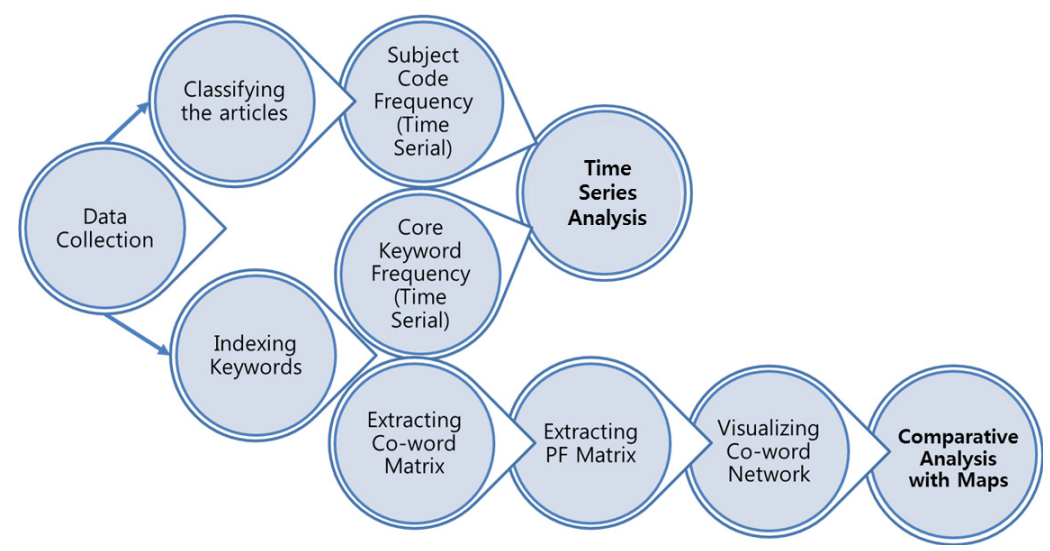

〈Figure 1〉 Research Design of This Study

1) There are 6 Korean academic societies in the field of LIS: the Korean Biblia Society for Library and Information Science, the Korean Library and Information Society, the Korean Society for Information Management, the Korean Society for Library and Information Science, Korean Society of Record Management and Archives, and Korean Society of Bibliography. 
〈Table 1〉 Number of IS Articles and their Authors, 2000-2011

\begin{tabular}{l|c|c|c|c|c|c}
\hline \multicolumn{1}{c|}{ Indicators } & Notion & JKBSLIS & JKLISS & JKOSIM & JKSLIS & Total \\
\hline Total \# of articles & $\mathrm{A}$ & 391 & 872 & 686 & 749 & 2,698 \\
\hline \# of selected articles (B/A × 100) & $\mathrm{B}$ & $85(22 \%)$ & $117(13 \%)$ & $586(85 \%)$ & $219(29 \%)$ & $1,007(37 \%)$ \\
\hline \# of authors in the selected articles & $\mathrm{C}$ & 125 & 176 & 975 & 334 & 1,610 \\
\hline $\begin{array}{l}\text { \# of articles by single author } \\
(\mathrm{D} / \mathrm{B} \times 100)\end{array}$ & $\mathrm{D}$ & $56(66 \%)$ & $76(65 \%)$ & $300(51 \%)$ & $139(63 \%)$ & $571(57 \%)$ \\
\hline \# of authors per articles (C/B) & $\mathrm{E}$ & 1.47 & 1.50 & 1.66 & 1.53 & 1.60 \\
\hline
\end{tabular}

(JKLIS)', 'Journal of the Korean Society for Information Management (JKOSIM)', and 'Journal of the Korean Society for Library and Information Science (JKSLIS).'

In this study, only IS research articles published in the leading academic Korean LIS journals between 2000 and 2011 were collected. Because the data collection was performed during May 8th - 17th in 2012 and the articles published in 2012 were not completely indexed in the database, the publications in 2012 and 2013 were not included in the dataset. To reduce accidental inclusion of non-IS articles in the sample, we cross-checked each article by analyzing titles and author keywords of all articles. Finally, the selection was limited to 1,007 research articles related to IS published in these 4 journals between 2000 and 2011. And the authors who were identified in any articles from the dataset (1,007 articles) were indexed for analyzing co-authorship pattern. $<$ Table $1>$ shows some properties of the IS research articles selected for the study. The total number of articles published in the four journals during the 12 years is 2,698. Only $37 \%$ (1,007 articles) are selected for the study. The total number of authors of the 1,007 IS articles was 1,610 , which amounted to 1.60 authors per article on average. The number of articles by a single author was 571 (57\%). It was also found that JKOSIM published mainly IS researches (586 out of total 686 papers are IS researches), while the portion of IS articles in JKSLIS and JKBLIS was $29 \%$ and $22 \%$ respectively. Only $13 \%$ in JKLISS were IS articles.

\subsection{Time-Series Analysis of the IS Research Articles}

The Time-Series analysis was conducted in regards to three aspects of IS research articles; 1) collaboration rate, 2) number of article distribution in subject categories, and 3) top keyword distribution with GI (Growth Index, Lee et al., 2011; Lee \& Choi, 2011). First, by analyzing articles selected from the four fore-mentioned journals, the study examined the extent of collaboration as indicator of the trends in patterns of single and joint authorship. The method of the study was to count the number of single author papers, the number of multiple author papers, and the number of all authors over two different time-windows.

Second, the study analyzed the theme of each article in order to present the number of article dis- 
tribution in subject categories. Consequently, the study developed the IS taxonomy based on the preceding works, such as Zins (2007), Zhao \& Stromann (2008), Seo (2010a), the current subject classification scheme of Information Science Abstract (ISA), and Encyclopedia of Library and Information Science (ELIS). After observing and checking the postings of each category, the study selected distinct subject categories which reflect all the IS field in existence today and then organized the subject categories. Finally, the IS taxonomy used in this study had 10 main subject categories and 40 subcategories (see $<$ Table $2>$ ).

Each article was assigned one subject scheme code based on its title, keywords and abstracts by the authors. Moreover, to confirm the subject allocation, each article was checked by the authors and a professor who majored in IS. With the results of subject allocation, the study conducted a diachronic analysis of each main subject in the 2000-2011 period. The analysis of the changes in research interests was divided into two equal 6-year periods: 2000-2005 and 2006-2011. Rather than taking a single snapshot of the scene observable at a given point in time, the aim was to present a series of such pictures, so that they may be compared and trends identified over time.

Third, the study selected keywords that had occurred over 50 times during the 12 years and then analyzed the year of distribution and increase slope. Analytical techniques were categorized as either quantitative/non-quantitative descriptive techniques or bibliometric descriptive techniques (such as year of publication, number of authors, and word frequency).

\subsection{Comparative Analysis of Intellectual Structure and Network}

Using keywords extracted from the titles and author keywords in Korea, a comparative analysis with co-word maps was also performed. This study used KLT v 2.0 (Kang, 2002), which has been developed for processing Korean texts, in order to stem and index nouns automatically. All syntactic stopwords were eliminated in the process of indexing, and content-based redundant words, such as 'research', or 'study', were also eliminated manually. There were no manual controls on keywords for disambiguating any semantic terms such as synonym, topically broad or narrow term, except controlling acronym, in order to avoid the bias. As a result, 1,125 unique terms were indexed, and the terms were translated into English by referring them to the English title and keywords of the data collection.

The reason to use Korean keywords is for assuring high accuracy and efficiency in the co-word analysis. Because the result of stemming English words can only provide stemmed root, we have to lemmatize the stemmed words again to visualize co-word map properly with them. Comparing to this, the result of stemming Korean words is the list of nouns which could be relatively easy to recognize and interpret. For example, given that the word of 'analysis (noun)' is stemmed by English stemmer, the stemmed result is the same to 'analys', which is hard to interpret 
in co-word map. The indexed result of corresponding Korean words of 'Bun-Suk (noun)' is , however, a complete noun form of 'Bun-Suk' which is easy to recognize in the map.

To see the knowledge structure precisely and to compare the changes over time, three different publication windows were also applied, and the timespan of each window was the same to that of the diachronic analysis. Among all of the unique terms, the terms that co-occurred with others in more than 6 different papers over the 12 years were used to make the co-word matrix for the 12-year time-window. To create the separate co-word matrixes for the first 6-year and the second 6- year time window, the terms that co-occurred with others in more than 3 different papers over each 6- year period were used.

For the first 6-year or last 6-year time-window, the word 'information' was excluded from the matrix because of its overly frequent co-occurrence with other keywords in order to identify knowledge structures more clearly from the networks. After making each co-word matrix, three networks were built in order to reveal the core backbone of the knowledge structure. And PCA was performed by using SPSS 21 to detect topical components in each co-word map. The number of topics were set as 10 as following the IS taxonomy scheme suggested in this study for the consistency of the time-serial analysis and the comparative analysis. NetworkWorkBench (NWB Team, 2006) was used for constructing PathFinder networks (Schvaneveldt, 1990), while NodeXL (Hansen, Shneiderman, \& Smith, 2010) was used for visualization. Analysis and visualization of knowledge networks can effectively assist in the discovery of new knowledge, as well as in the management and use of existing knowledge resources.

\section{Results and Discussion}

\subsection{Subject Schemes and Research Productivity in Subjects over Time}

\subsubsection{Number of Article Distribution by Main Categories}

The selected 1,007 research articles were classified according to IS taxonomy scheme. The theme of each article was primarily analyzed based on its title, keywords and abstracts. Consequently, there are a number of heavily posted categories, as well as a small number of categories with only a few postings (see $<$ Table $2>$ ).

The most highly posted subject category, that is the most productive area, was Information Organization' (172 articles) that made up for 17.1 percent of all articles. The next productive areas are 'Information Retrieval' (149 or 14.8\%), 'Information System Design \& Evaluation' (142 or 14.1\%), and 'Information System Application' (141 or 14.0\%). 'Information Organization' which covers classification, cataloging, subject analysis, etc., has been traditionally regarded as the core area in the field of Library and Information Science.

Recently, the phenomena and activities surrounding the organization of information in web environments such as metadata, tagging, taxonomies, ontol 


\section{〈Table 2〉 Number of Articles in IS Subject Categories}

\begin{tabular}{|c|c|c|c|c|}
\hline Class & Main Categories & Sub-Categories & \multicolumn{2}{|c|}{$\#$ of Articles $(\%)$} \\
\hline \multirow{5}{*}{$\begin{array}{l}\text { Information } \\
\text { Nature }\end{array}$} & \multirow[t]{3}{*}{ 1. Basic Concepts } & 1.1 Value, Quality, Properties of Information & $1(0.1)$ & \multirow[b]{3}{*}{$21(2.1)$} \\
\hline & & 1.2 Definition, Theories, Methodologies & $8(0.87)$ & \\
\hline & & 1.3 Information Economics & 12(1.2) & \\
\hline & \multirow[t]{2}{*}{ 2. Informetrics } & 2.1 Bibliometrics, Citation Analysis, Webometrics & $39(3.9)$ & \multirow[b]{2}{*}{$87(8.6)$} \\
\hline & & 2.2 Intellectual Structure, Research Trends & $48(4.8)$ & \\
\hline \multirow{3}{*}{$\begin{array}{l}\text { Information } \\
\text { Use }\end{array}$} & \multirow{3}{*}{$\begin{array}{l}\text { 3. Information Use } \\
\text { \& Users }\end{array}$} & 3.1 Information Need, Information Use, Cognitive Process & $12(1.2)$ & \multirow[b]{3}{*}{$72(7.1)$} \\
\hline & & 3.2 Information Seeking/Searching Behaviors & $35(3.5)$ & \\
\hline & & 3.3 User Studies, User Perception, User Surveys & $25(2.5)$ & \\
\hline \multirow{11}{*}{$\begin{array}{l}\text { Information } \\
\text { Processing }\end{array}$} & \multirow{5}{*}{$\begin{array}{l}\text { 4. Information } \\
\text { Organization }\end{array}$} & 4.1 Classification Theory, Taxonomies & $11(1.1)$ & \multirow[b]{5}{*}{ 172(17.1) } \\
\hline & & 4.2 Cataloging Theory, Tagging, MARC, FRBR & $28(2.8)$ & \\
\hline & & 4.3 Metadata, DC, Descriptors & $59(5.9)$ & \\
\hline & & 4.4 Thesauri, Ontologies, Semantics & $58(5.8)$ & \\
\hline & & 4.5 Indexing, Automatic Indexing / Abstracting & 16(1.6) & \\
\hline & \multirow{6}{*}{$\begin{array}{l}\text { 5. Information } \\
\text { Retrieval }\end{array}$} & 5.1 IR Model: Boolean, Vector, Fuzzy Set, Probabilistic & 12(1.2) & \multirow[b]{6}{*}{ 149(14.8) } \\
\hline & & 5.2 Automatic Classification & $57(5.7)$ & \\
\hline & & 5.3 Search Strategies, Query Formulation, Query Expansion & $18(1.8)$ & \\
\hline & & 5.4 IR Performance Evaluation: Ranking/Relevance, Feedback & $14(1.4)$ & \\
\hline & & 5.5 Content-Based Searching, Semantic Retrieval Personalization & $28(2.8)$ & \\
\hline & & 5.6 Web Searching, Search Engine, Agent & $20(2.0)$ & \\
\hline \multirow{13}{*}{$\begin{array}{l}\text { Information } \\
\text { System }\end{array}$} & \multirow{4}{*}{$\begin{array}{l}\text { 6. Information } \\
\text { System Design } \\
\text { \& Evaluation }\end{array}$} & 6.1 System Analysis \& Design, Web Design, IA & $34(3.4)$ & \multirow[b]{4}{*}{ 142(14.1) } \\
\hline & & 6.2 HCI, Search Interface Design & $33(3.3)$ & \\
\hline & & 6.3 Systems Evaluation, Web Site Usability, Accessibility & $52(5.2)$ & \\
\hline & & 6.4 DB Quality Evaluation, Web Resource/ Contents Evaluation & $23(2.3)$ & \\
\hline & \multirow{4}{*}{$\begin{array}{l}\text { 7. Information } \\
\text { System } \\
\text { Application }\end{array}$} & 7.1 Digital Libraries, KMS, Customized Information System & $67(6.7)$ & \multirow[b]{4}{*}{ 141(14.0) } \\
\hline & & 7.2 Digitization, SGML / HTML / XML, OCR & $15(1.5)$ & \\
\hline & & 7.3 Digital Archiving, Digital Repository, Web Archiving & $49(4.9)$ & \\
\hline & & 7.4 Electronic Resource Management & 10(1.0) & \\
\hline & \multirow{5}{*}{$\begin{array}{l}\text { 8. Information } \\
\text { Network \& } \\
\text { Technology }\end{array}$} & 8.1 Library Network, Library Portal, Gateway Pathfinders & $14(1.4)$ & \multirow[b]{5}{*}{$71(7.1)$} \\
\hline & & 8.2 Internet, Browsers, Web, Web Site & $25(2.5)$ & \\
\hline & & 8.3 Social Networking, OpenURL, Web Linking & $11(1.1)$ & \\
\hline & & 8.4 Record Management, ERM, DRM & $8(0.8)$ & \\
\hline & & 8.5 Information Standards & $13(1.3)$ & \\
\hline \multirow{8}{*}{$\begin{array}{l}\text { Information } \\
\text { Utilization }\end{array}$} & \multirow[t]{3}{*}{ 9. Information Issues } & 9.1 Information Policies, Information Ethics & $5(0.5)$ & \multirow[b]{3}{*}{$52(5.2)$} \\
\hline & & 9.2 Information Literacy/Flows, Information Society & $24(2.4)$ & \\
\hline & & 9.3 Legal Issues, Intellectual Property Protection Opyright & $23(1.3)$ & \\
\hline & \multirow{5}{*}{$\begin{array}{l}\text { 10. Resources \& } \\
\text { Services }\end{array}$} & 10.1 E-Journal / E-Book, Scholarly Communication & $20(2.0)$ & \multirow{6}{*}{$100(9.9)$} \\
\hline & & 10.2 Information Sources, Open Access & $16(1.6)$ & \\
\hline & & 10.3 Information Professionals, Education & 19(1.7) & \\
\hline & & 10.4 Information Services, Document Delivery Services & $37(3.7)$ & \\
\hline & & 10.5 Information Centers & $8(0.8)$ & \\
\hline & Total & & 1,00 & \\
\hline
\end{tabular}


ogy etc. are becoming hot issues. Therefore, the research on information organization has steadily been heavy and expanded. 'Information Retrieval' is still a predominant core area in Information Science. The early main concerns in IR were retrieving and searching methods and evaluation. These led to a range of models and experiments until the 1990's (Seo, 2010a), since when interest have been broadening to include now computer-based handling of multimedia information, employment of new methods from other disciplines, and mass information handling in virtual environments. In relation to the sphere of information systems or digital libraries, the development of search engines and the Internet as a technological tool have brought about studies connected to metadata, intelligent retrieval, website design, and digital systems based on the Web into the heart of research activity.

The second ranked category includes 'Resources \& Services' (100 or 9.9\%), 'Informetrics' (87 or $8.6 \%$ ), 'Information Use and Users' (72 or 7.1\%), and 'Information Network and Technology' (71 or 7.1\%). It can be assumed that the profound changes in information technologies have also caused research productivity in the field of system services, user studies on the new systems or services, and technology application itself. As Informetrics, which encompasses the fields of bibliometrics, webometrics, and scientometrics, has expanded and become more useful during the $2000 \mathrm{~s}$, its research productivity is marked within the second group. The lowest posting areas are 'Information Issues' (52 or 5.2\%) and 'Basic Concepts' (21 or $2.1 \%$ ). It is hardly surprising that theoretical or policy research dealing with information value, IS theory, legal issues, and the like, has decreased as Information Science has become established.

In terms of subcategories shown in $<$ Table $2>$, the most highly posted areas were 'digital library' (67 postings), 'metadata' (59), 'thesauri' (58), 'automatic classification' (57), 'system evaluation' (52), 'digital archiving' (49), and 'intellectual structure analysis' (48). The second most highly posted areas were 'bibliometrics' (39), 'information service' (37), 'information seeking' (35), 'system analysis and design' (34), and 'HCI' (33). These 12 subcategories belong to all main categories except 'Basic Concepts', 'Information Network \& Technology', and 'Information Issues.' The lowest posted subcategories were 'information properties' (1), 'theories' (8), and 'ERM' (8).

During the last twelve-year period, the emphasis of IS research in Korea was placed on information organization and processing connected with intelligent retrieval on the web. This phenomenon is remarkably consistent with previous findings, but it is interesting that 'System Design \& Evaluation' which attempts to develop new information systems or interfaces and to evaluate their usability and effectiveness in the market, was highly productive compared to other research (Zins, 2007; Zhao \& Stromann, 2008).

\subsubsection{Number of Article Distribution in Main Categories at Journal-level Analysis}

The papers published in the four journals (JKBSLIS, JKLISS, JKOSIM, and JKSLIS) were analyzed in 
〈Table 3〉 Subject distribution by main category in the journals

\begin{tabular}{l|c|c|c|c|c}
\hline \multicolumn{1}{c|}{ Main Category } & JKBSLIS & JKLISS & JKOSIM & JKSLIS & Total \\
\hline Basic Concepts & $0(0)$ & $1(0.9)$ & $13(2.2)$ & $7(3.2)$ & $21(2.1)$ \\
\hline Informetrics & $4(4.7)$ & $11(9.4)$ & $52(8.9)$ & $20(9.1)$ & $87(8.6)$ \\
\hline Information Use \& Users & $3(3.5)$ & $7(6.0)$ & $45(7.7)$ & $17(7.8)$ & $72(7.1)$ \\
\hline Information Organization & $14(16.5)$ & $33(28.2)$ & $91(15.5)$ & $34(15.5)$ & $172(17.1)$ \\
\hline Information Retrieval & $7(8.2)$ & $17(14.5)$ & $99(16.9)$ & $26(11.9)$ & $149(14.8)$ \\
\hline System Design \& Evaluation & $26(30.6)$ & $11(9.4)$ & $70(11.9)$ & $35(16.0)$ & $142(14.1)$ \\
\hline System Application & $15(17.6)$ & $13(11.1)$ & $76(13.0)$ & $37(16.9)$ & $141(14.0)$ \\
\hline Network \& IT & $7(8.2)$ & $15(12.8)$ & $35(6.0)$ & $14(6.4)$ & $71(7.1)$ \\
\hline Information Issues & $4(4.7)$ & $5(4.2)$ & $30(5.1)$ & $13(5.9)$ & $52(5.2)$ \\
\hline Information Services & $5(5.9)$ & $4(3.4)$ & $75(12.8)$ & $16(7.3)$ & $100(9.9)$ \\
\hline \multicolumn{1}{c}{ Total } & $85(100)$ & $117(100)$ & $586(100)$ & $219(100)$ & $1,007(100)$ \\
\hline
\end{tabular}

terms of subject distribution. The result indicates that each of the four journals has its own characteristics. That is, information organization research is predominant in the JKLISS whose articles heavily covered library practice, while system design research is predominant in the JKBLISS whose articles usually covered current hot topics and special issues. The other two journals, JKOSIM and JKSLIS, which have quite a long history and cover all areas in IS and LIS respectively, do not show one predominant subject area, so that the distribution rates of the top four subject areas are similar. As $<$ Table $3>$ demonstrates, the highly posted three subject categories in JKBLIS were 'System Design \& Evaluation' (30.6\%), 'System Application' (17.6\%), and 'Information Organization' (16.5\%). Those categories of JKLISS were 'Information Organization' (28.2\%), 'Information Retrieval' (14.5\%) and 'Network \& IT' (12.8\%). Those of JKOSIM were 'Information Retrieval' (16.9\%), 'Information Organization' (15.1) and 'System Application' (13.0\%). Finally, those of JKSLLIS are 'System Application'
(16.9\%), 'System Design \& Evaluation' (16.0\%) and 'Information Organization' (15.5\%).

\subsection{Time-Series Analysis}

\subsubsection{Changes in Co-authorship Patterns over Time}

The authorship pattern was analyzed to determine the collaborative trends. As the last few decades have been witness to a collaborative endeavors (Mukherjee, 2010), the study also found an increasing trend towards collaborative research. The author data consist of 1,610 authors for 1,007 articles, while 571 articles (57.2\%) were by single authors (see < Table $4>$ ). The number of articles written by two authors, three authors, four authors, five authors, and more than six authors was 329 (32.7\%), 64 (6.4\%), 22 (2.2\%), $8(7.9 \%), 8(7.9 \%)$ respectively. The total degree of collaboration (number of articles by joint authors / total number of articles) is 0.43 , that is, less than half of the total articles were written by joint authors. 
〈Table 4〉 Authorship pattern and degree of collaboration

\begin{tabular}{|c|c|c|c|c|c|c|c|c|c|}
\hline \multirow[b]{2}{*}{ Indicator } & \multicolumn{4}{|c|}{ The $1^{\text {st }}$ Period (2000-2005) } & \multicolumn{4}{|c|}{ The $2^{\text {nd }}$ Period (2006-2011) } & \multirow{2}{*}{$\begin{array}{c}\text { 2000-2011 } \\
\text { Total }\end{array}$} \\
\hline & $\begin{array}{c}2000- \\
2001\end{array}$ & $\begin{array}{c}2002- \\
2003\end{array}$ & $\begin{array}{c}2004- \\
2005\end{array}$ & Total & $\begin{array}{c}2006- \\
2007\end{array}$ & $\begin{array}{c}2008- \\
2009\end{array}$ & $\begin{array}{c}2010- \\
2011\end{array}$ & Total & \\
\hline \# of single author papers $(\mathrm{A})$ & 98 & 102 & 111 & 311 & 83 & 79 & 98 & 260 & 571 \\
\hline \# of multiple author papers (B) & 51 & 58 & 71 & 180 & 105 & 82 & 69 & 256 & 436 \\
\hline \# of papers $(\mathrm{C})$ & 149 & 160 & 182 & 491 & 188 & 161 & 167 & 516 & 1,007 \\
\hline \# of authors (D) & 219 & 238 & 273 & 730 & 344 & 279 & 257 & 880 & 1,610 \\
\hline degree of collaboration $(\mathrm{B} / \mathrm{C})$ & 0.34 & 0.36 & 0.39 & 0.36 & 0.56 & 0.51 & 0.41 & 0.49 & 0.43 \\
\hline
\end{tabular}

Comparing the co-authorship pattern trends between the two publication windows - the $2000-05$ and 2006 - 11 window, the collaborations seemed to grow in prevalence (see $<$ Table $4>$ ). In the first period (2000-2005), 63.3\% (311) of all articles were single-authored, while the remaining 36.7\% (180) were coauthored. However, in the second period (20062011), the percentage of single-authored articles dipped to $50.3 \%$ (260), while that of coauthored articles surged to $49.6 \%$ (256).

To provide a more granular analysis, the data, which had been captured on a two-year basis, were disaggregated and expressed in the degree of collaboration to be compared among those four journals. From $<$ Table $4>$, it can be observed that solo-authored articles dominated in the early 2000 s, but the percentage of coauthored articles rose to over 50 percent from 2006 through 2009. Hence, IS research in Korea follows a trend of collaborative research. The study also analyzed the authorship patterns of four journals by two-year periods (See Figure 3). During the 2000-2011 period, JKOSIM had the highest degree of collaboration (0.49), followed by JKSLIS (0.37), JKLISS (0.35), and JKBLIS (0.34). The highest degree of collaboration was reached in JKBLIS $(0.64)$ in the years 2008-2009, followed by 0.60 in JKOSIM, in the years 2006-2007. JKBLIS also marked the lowest degree of collaboration (0.11) in the years 2002-2003, so we could see that the co-authorship in $J K B L I S$ was growing sharply.

\subsubsection{Changes in Research Subject Patterns over Time}

The study conducted a diachronic analysis of each main subject during the 2000-2011 period. For the purpose of detecting the shifts in the distribution of the subject during these 12 years, the study, first of all, compared the research trends between the two 'publication windows', that is, the 2000-2005 (denoted as $P-1$ ) and the 2006-2011(denoted as $P$-2), then it calculated the slope of change over time. As a result, the subject areas which showed increasing research activities were 'Informetrics', 'Information Organization', 'Information Retrieval', 'Basic Concepts', and 'Information Use \& Users', while the decreasing subject areas were 'Information System Application', and 'Resources \& Services.' On the other hand, 'Information System Design \& Evaluation' and 'Information Network and Technology' did not show big change of productivity (see $<$ Table $5>$ ). 
〈Table 5〉 Change in research productivity of each Subject area over time

\begin{tabular}{l|c|c|c|c}
\hline \multicolumn{1}{c|}{ Main Categories } & P-1 & P-2 & Total & Growth Rate \\
\hline 1. Basic Concepts & $9(1.83)$ & $12(2.33)$ & 21 & 0.25 \\
\hline 2. Informetrics & $28(5.7)$ & $59(11.43)$ & 87 & 0.53 \\
\hline 3. Use \& Users & $34(6.92)$ & $38(7.36)$ & 72 & 0.11 \\
\hline 4. Organization & $77(15.68)$ & $95(18.41)$ & 172 & 0.19 \\
\hline 5. Retrieval & $70(14.26)$ & $79(15.31)$ & 149 & 0.11 \\
\hline 6. Design & $74(15.07)$ & $68(13.18)$ & 142 & -0.09 \\
\hline 7. System & $85(17.31)$ & $56(10.85)$ & 141 & -0.52 \\
\hline 8. Network & $34(6.92)$ & $37(7.17)$ & 71 & 0.08 \\
\hline 9. Issues & $24(4.89)$ & $28(5.43)$ & 52 & 0.14 \\
\hline 10. Services & $56(11.41)$ & $44(8.53)$ & 100 & -0.27 \\
\hline \multicolumn{1}{c|}{ Total } & $491(100)$ & $516(100)$ & 1,007 & \\
\hline
\end{tabular}

$<$ Figure $2>$ shows the distribution change of 10 subject categories by year. The subject areas which showed sharp rise in research activities in recent years were 'Informetrics' and 'Information Organization.' Especially, research in the field of Informetrics increased sharply since 2009 , when Webometrics, the study of web-based phenomena using quantitative techniques, expanded for the purpose of analyzing various aspects of the web and its derived data. Research of 'Information Organization' and 'Information Retrieval' peaked between 2004 and 2007, but these researches have been slowing down lately. The research of 'System Application' in 2004 and that of 'Design and Evaluation' in 2007 were highly productive (up to $20 \%$ ), but lately these researches have been decreasing sharply.

During the early 2000s in Korea, many libraries and information centers, generally, built new webbased system and interface, so that many researchers conducted research of the new design and new systems and then evaluated their performance. However, recently, they lost some interest in the application and evaluation since the new design or new systems have become more common. On the other hand, it is observed that there was little or no attention paid to theoretical conceptualization and policy studies (see $<$ Figure $2>$ ).

In fact, in the 2000's, the advent of new information environment facilitated researches on ontology, multimedia retrieval, user-centered design, and user-based searching connected with information seeking studies. Also, regardless of the changes of information technologies and environment, interest in informetric studies grew rapidly in recent years because of the availability of new significant sources of information about scholarly communication.

Next, the study identified the change in research trends in terms of sub-subject categories, comparing the two periods (2000-2005 and 2006-2011). <Table $6>$ shows the highly posted top 12 subcategories and the change in the subcategories between the two periods. The figure also demonstrates that the 

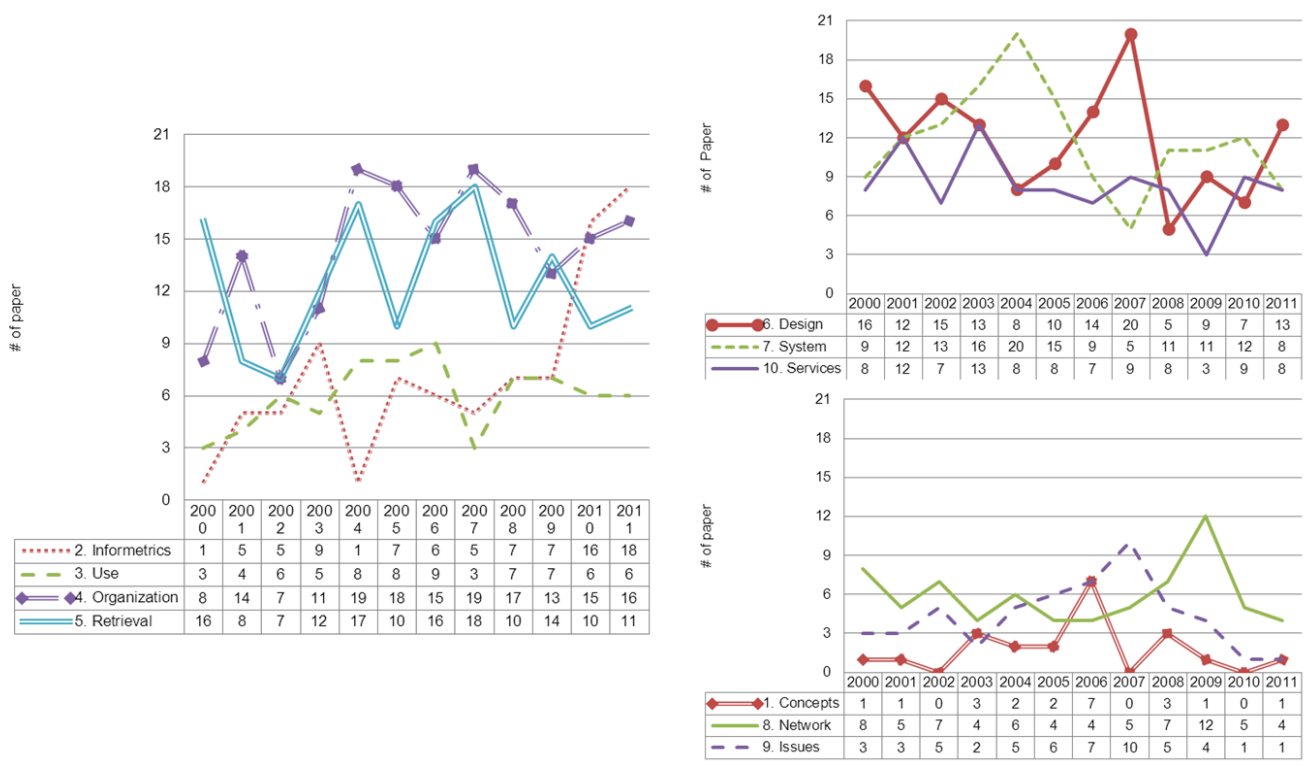

〈Figure 2〉 Growth rate of research productivity in subject area

〈Table 6〉 Highly Posted Sub-categories

\begin{tabular}{l|c|c|c|c|c|c}
\hline \multirow{2}{*}{ Sub-category } & \multicolumn{3}{|c|}{ \# of paper } & \multicolumn{3}{c}{ Ratic to total } \\
\cline { 2 - 7 } & P-1 & P-2 & Total & P-1 & P-2 & Total \\
\hline Digital Library & 41 & 26 & 67 & 8.35 & 5.04 & 6.65 \\
\hline Metadata & 25 & 34 & 59 & 5.09 & 6.59 & 5.86 \\
\hline Ontologies & 24 & 34 & 58 & 4.89 & 6.59 & 5.76 \\
\hline Auto Classification & 25 & 32 & 57 & 5.09 & 6.20 & 5.66 \\
\hline System Evaluation & 24 & 28 & 52 & 4.89 & 5.43 & 5.16 \\
\hline Digital Archiving & 24 & 25 & 49 & 4.89 & 4.84 & 4.87 \\
\hline Intellectual Structure & 18 & 30 & 48 & 3.67 & 5.81 & 4.77 \\
\hline Bibliometrics & 10 & 29 & 39 & 2.04 & 5.62 & 3.87 \\
\hline Information Service & 21 & 16 & 37 & 4.28 & 3.10 & 3.67 \\
\hline Information Behaviors & 16 & 19 & 35 & 3.26 & 3.68 & 3.48 \\
\hline System Design & 22 & 12 & 34 & 4.48 & 2.33 & 3.38 \\
\hline HCI Total & 12 & 21 & 33 & 2.44 & 4.07 & 3.28 \\
\hline & 262 & 306 & 568 & 100 & 100 & 100 \\
\hline
\end{tabular}

highly posted top 12 subcategories were 'digital libraries' (67), 'metadata' (59), 'ontologies' (58), 'automatic classification' (57), 'system evaluation' (52), 'digital archiving' (49), 'intellectual structure' (48), 'bibliometrics' (39), 'information services' (37), 'information behaviors' (35), 'system design' (34), and 'HCI' (33). 
Among the top 12 sub-subject areas, the most productive three areas in the $1^{\text {st }}$ period were 'digital library', 'metadata', and 'automatic classification', but those in the $2^{\text {nd }}$ period were 'ontology', 'metadata', and 'automatic classification.' It is also indicated that the common subjects were 'metadata' and 'automatic classification', meaning that information scientists kept on researching access point processing and automatic document analysis. However, it is clear that main interests in the late 2000s were leaning towards Informetrics (bibliometrics \& intellectual structure) and Information Organization (ontology $\&$ metadata) in the late 2000 s.

In addition, the study also analyzed the change between the $1^{\text {st }}$ period and $2^{\text {nd }}$ period in the representation of subcategories. In essence, over the years, the presence of the subject areas dealing with information services and legal issues was reduced, while the presence of those using new analytical methods or tools such as informetrics, ontology and HCI was increased. Interestingly, in the field of Information Retrieval, the number of researches on IR model and evaluation were decreased, but the number of researches on multimedia IR and clustering/social network analysis for IR were increased. $<$ Table 6> demonstrates that 'Bibliometrics' has grown most significantly in distribution, followed by 'Research Trends', 'Information Flow', 'Ontology', 'HCI', 'Metadata', 'Multimedia Retrieval', 'Social Network', 'Automatic Classification', and 'Theories.' Conversely, sub-subject areas with the highly decreased rate were 'Information Center', 'Information Services', 'Legal Issues', 'ERM', 'Digitalization',
'DB Evaluation', 'System Design', 'IR Model', and 'IR Evaluation.'

\subsubsection{Changes in 'Top' Keywords Growth Rate over Time}

To identify top keywords, all keywords from the 1,007 articles published during the 12 years were ranked according to the number of occurrence in the title and author keywords fields. The rationale behind analyzing top keywords was based on the assumption that these highly frequent terms are represented in the leading subject areas in IS. The total number of unique keywords in 2000-2011 was 2,860 (the number of total keywords entries being 8,821). There are 1,672 distinct keywords (the number of total entries being 4,197) in the $2000-2005$ period, while there were 1,811 distinct keywords (the number of total entries being 4,624) in the $2006-2011$ period, the top $0.1 \%$ of all keywords ( 3 keywords) occurs over 142 times, and the top 1\% (29 keywords) occurs over 35 times.

The most frequently occurring keywords were 'Web' (150), followed by 'retrieval' (142), 'evaluation' (142), 'system' (134), 'model' (121), 'users' (116), 'use' (105), 'library' (104), and etc. (see < Table 7>). When compared to Rorissa \& Yuan's (2012) study which analyzed the frequency of keyword terms in information retrieval dataset (2000-2009), showing the the most frequently occuring keywords (top $0.6 \%$ ), it is evdient that these two studies discovered some common words, such as 'retrieval', 'internet', 'system', 'Web', 'management', 'technology', and 'knowledge.' Despite the dynamic changes brought on by new 
〈Table 7〉 Top Keywords Distribution and Gl

\begin{tabular}{l|c|c|c|c|c|c|c|c|c|c|c|c|c|c}
\hline Keyword & Year & '01 & '02 & '03 & '04 & 05 & '06 & '07 & ’08 & '09 & '10 & '11 & Total & GI \\
\hline Web & 14 & 13 & 14 & 7 & 20 & 6 & 13 & 11 & 8 & 14 & 14 & 16 & 150 & 0.50 \\
\hline Retrieval & 8 & 15 & 18 & 15 & 11 & 5 & 20 & 8 & 12 & 4 & 9 & 17 & 142 & 0.48 \\
\hline Evaluation & 12 & 10 & 17 & 13 & 15 & 7 & 11 & 9 & 4 & 13 & 18 & 13 & 142 & 0.50 \\
\hline System & 12 & 11 & 7 & 16 & 15 & 14 & 15 & 7 & 10 & 9 & 8 & 10 & 134 & 0.47 \\
\hline Model & 6 & 10 & 12 & 12 & 11 & 20 & 15 & 13 & 5 & 6 & 5 & 6 & 121 & 0.45 \\
\hline Users & 11 & 10 & 6 & 9 & 12 & 8 & 12 & 8 & 10 & 14 & 3 & 13 & 116 & 0.50 \\
\hline Use & 3 & 8 & 9 & 9 & 7 & 11 & 13 & 10 & 7 & 6 & 9 & 13 & 105 & 0.54 \\
\hline Library & 8 & 3 & 15 & 7 & 9 & 7 & 9 & 6 & 9 & 10 & 8 & 13 & 104 & 0.53 \\
\hline Metadata & 5 & 11 & 6 & 6 & 8 & 7 & 11 & 6 & 7 & 5 & 6 & 11 & 89 & 0.51 \\
\hline Korea & 9 & 7 & 9 & 8 & 7 & 8 & 3 & 4 & 5 & 13 & 6 & 10 & 89 & 0.50 \\
\hline Services & 3 & 6 & 8 & 2 & 9 & 3 & 5 & 7 & 7 & 8 & 6 & 11 & 75 & 0.57 \\
\hline Digital & 6 & 3 & 4 & 6 & 2 & 4 & 4 & 7 & 6 & 2 & 5 & 8 & 57 & 0.53 \\
\hline Management & 4 & 4 & 1 & 5 & 8 & 2 & 6 & 4 & 2 & 6 & 9 & 4 & 55 & 0.55 \\
\hline Ontology & 8 & 5 & 0 & 0 & 6 & 7 & 8 & 8 & 7 & 2 & 0 & 3 & 54 & 0.46 \\
\hline Internet & 4 & 3 & 5 & 15 & 6 & 4 & 4 & 0 & 0 & 9 & 2 & 2 & 54 & 0.42 \\
\hline Knowledge & 1 & 1 & 1 & 6 & 5 & 4 & 2 & 3 & 8 & 4 & 6 & 4 & 45 & 0.60 \\
\hline Technology & 1 & 5 & 3 & 1 & 4 & 2 & 0 & 4 & 2 & 2 & 3 & 2 & 29 & 0.48 \\
\hline
\end{tabular}

developments and new technologies, the dominance of the terms 'retreival' and 'system' provide some indication of the stability and homogeneity of the field during the 2000s. The analyses of most frequently ocuring keywords in 3 distinct periods during the 12-year, demonstrated that system oriented words, such as 'system', 'library', and 'Internet' occrrured more often in the early 2000s, while words releated to Web-based techniques such as 'metadata', 'ontology', and 'knowledge' occurred more during the mid-2000s. During the late 2000s, 'user (or use)', 'evalution', and 'service' were most frequently present. Therefore, it can be assumed that the matter of common interest in IS research has first moved from new technology application to Web-based technique utilization, and then to their evaluation based on use and users.

The table also demonstrates that the occurrences of the words 'Internet', 'model' and 'technology' sharply decreased, while those of words such as 'knowledge', 'service', 'management', 'use', 'library', 'digital', and 'management', were increased in the 2000-2011 period. It can be concluded that the frequency of keywords related to knowledge organization and retrieval services in Web environments have been growing. This brings about the apprehension that IS in Korea may have been veering too much towards Web application and losing sight of system and technolgogy. 


\subsection{Changes in Major Research Domains in Korean Information Science Studies}

Information science has progressed by leaps and bounds due to the ubiquity and increased use of new technologies such as the Internet, the Web, digital libraries, multimedia processing, and other means of information access. It is interesting to investigate the extent to which these new developments have changed the IS literature landscape. This study constructed an IS network by analyzing terms co-occurring with others in more than 6 different papers over a 12- year period (see $<$ Figure $3>$ ). The keywords are loaded in one of 10 specialties or 1 'general' category2) as a result of PCA and each specialty is colored differently in $<$ Figure $3>$. Each specialty and pertinent keywords are shown in $\langle$ Table $8>$.

The keyword of 'evaluation' links 'Resource \& Service' which is composed of 4 terms, and 'Library Services' which is composed of 18 terms and the keyword is located in the center of IS intellectual structure by connecting the most of specialties. This highlights the rising emphasis on 'evaluation', as well as the importance of 'user' which connect 'Use \& Users' to 'Library Services.' Research in Web usability and digital library services/applications based on user evaluation is quite visible and active with the 11 keywords in 'Library \& Web 2.0' specialty.

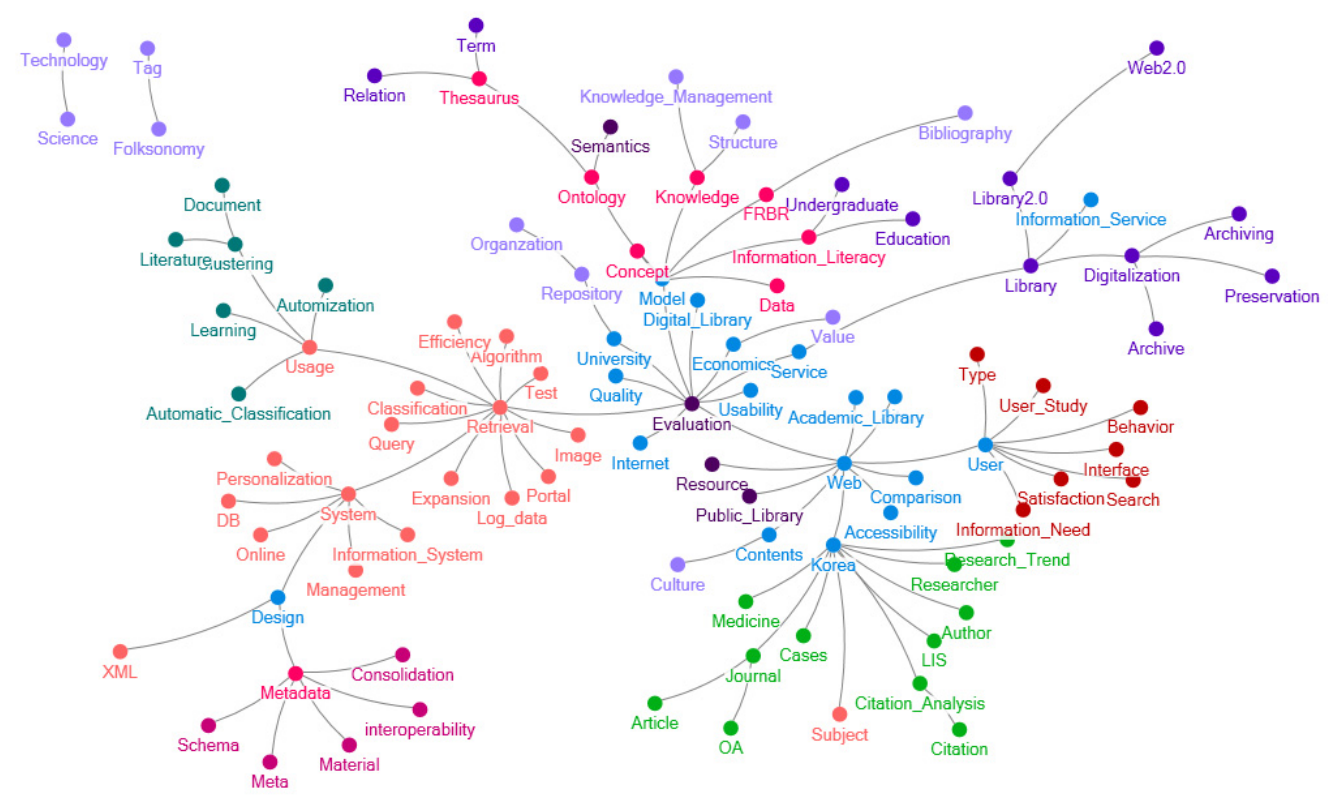

〈Figure 3〉Intellectual Structure of Information Science research in Korea, 2000-2011

2) The 'general' category consists of the keywords which were loaded to all of 10 specialties lower than 0.1. 
$\langle$ Table 8〉 Research domains and pertinent keywords in Information science research of Korea

\begin{tabular}{l|l}
\hline \multicolumn{1}{c|}{ Specialty } & \multicolumn{1}{c}{ Keywords } \\
\hline Library Services (18) & $\begin{array}{l}\text { Contents, Design, Economics, User, University, Academic Library, Digital Library, } \\
\text { Model, Comparison, Usability, Site, Service, Web, Internet, Accessibility, Information } \\
\text { Service, Quality, Korea }\end{array}$ \\
\hline $\begin{array}{l}\text { Information System Application } \\
\text { (11) }\end{array}$ & $\begin{array}{l}\text { Efficiency, Log Data, Classification, System, Test, Algorithm, Image, Usage, Query, } \\
\text { Portal, Expansion }\end{array}$ \\
\hline Informetrics (11) & $\begin{array}{l}\text { Article, LIS, Research Trend, Researcher, OA, Medicine, Citation, Citation Analysis, } \\
\text { Author, Journal, Cases }\end{array}$ \\
\hline Library \& Web 2.0 (11) & $\begin{array}{l}\text { Archive, Library, Relation, Education, Undergraduate, Library2.0, Digitalization, } \\
\text { Preservation, Archiving, Term, Web2.0 }\end{array}$ \\
\hline IR \& Information System (8) & $\begin{array}{l}\text { XML, Personalization, Retrieval, Management, DB, Online, Information System, } \\
\text { Subject }\end{array}$ \\
\hline $\begin{array}{l}\text { Information Organization } \\
\text { And Metadata (8) }\end{array}$ & $\begin{array}{l}\text { FRBR, Information Literacy, Concept, Data, Metadata, Thesaurus, Ontology, } \\
\text { Knowledge }\end{array}$ \\
\hline Use \& Users (7) & Behavior, Satisfaction, Type, User Study, Interface, Information Need, Search \\
\hline Text Mining (6) & Literature, Document, Automization, Automatic Classification, Clustering, Learning \\
\hline Information System Design (5) & Meta, interoperability, Schema, Material, Consolidation \\
\hline Resource \& Services (4) & Public Library, Semantics, Resource, Evaluation \\
\hline General (11) & $\begin{array}{l}\text { Value, Science, Structure, Organization, Technology, Repository, Culture, Bibliography, } \\
\text { Knowledge Management, Tag, Folksonomy }\end{array}$ \\
\hline
\end{tabular}

The domain of Information retrieval research is getting wider nowadays because the research interests in the domain include not only user-centered design in the Web environment (UI-oriented) but also the users' interaction with information retrieval systems (HCI-related), which are more specific than user information seeking behavior in general (Rorissa \& Yuan, 2012). In Seo's study (2010a/2010b), which analyzed IS domains based on JASIST, Information Retrieval and Informetrics are identified as the most prominent research areas, but User Studies is not identified as the one of the largest specialties. These differences indicate the major characteristics of Korean IS research and the finding of this study is also supported by other related research (Cho, 2011; Park \& Song, 2013). Research of 'experimental retrieval' and related information processing, considered the core area of IS, are also prominent in Korea, but the closely connected research areas are different: research in the 'IR \& Information System' area is directly connected to the 'Resource \& Services' and 'Library Services.' In addtion to that, 'Information Organization \& Metadata', as a subset of information processing in the suggested IS taxomony scheme, is also directly connected to the 'Library Service.' This finding shows that 'evaluation' is a hub word connecting all related research areas in Korean IS studies. This positioning implies that Web-based information system and services embedded and implemented in information service infrastructure comprise a fundamental environment in Korean IS practices and pertinent research. 
Next, the study revealed the backbone of the knowledge structure based on the analysis of 80 terms co-occurring with others in more than 3 different papers published from 2000 to 2005 and the identified specialties with pertinent keywords were shown in
$<$ Table $9>$.

$<$ Figure $4>$ indicates that 'IR(Information Retrieval)' and 'Use \& Users' located in the center spread out core nodes such as 'Informetrics', 'Library Services', and 'Information Organization' as themes of main

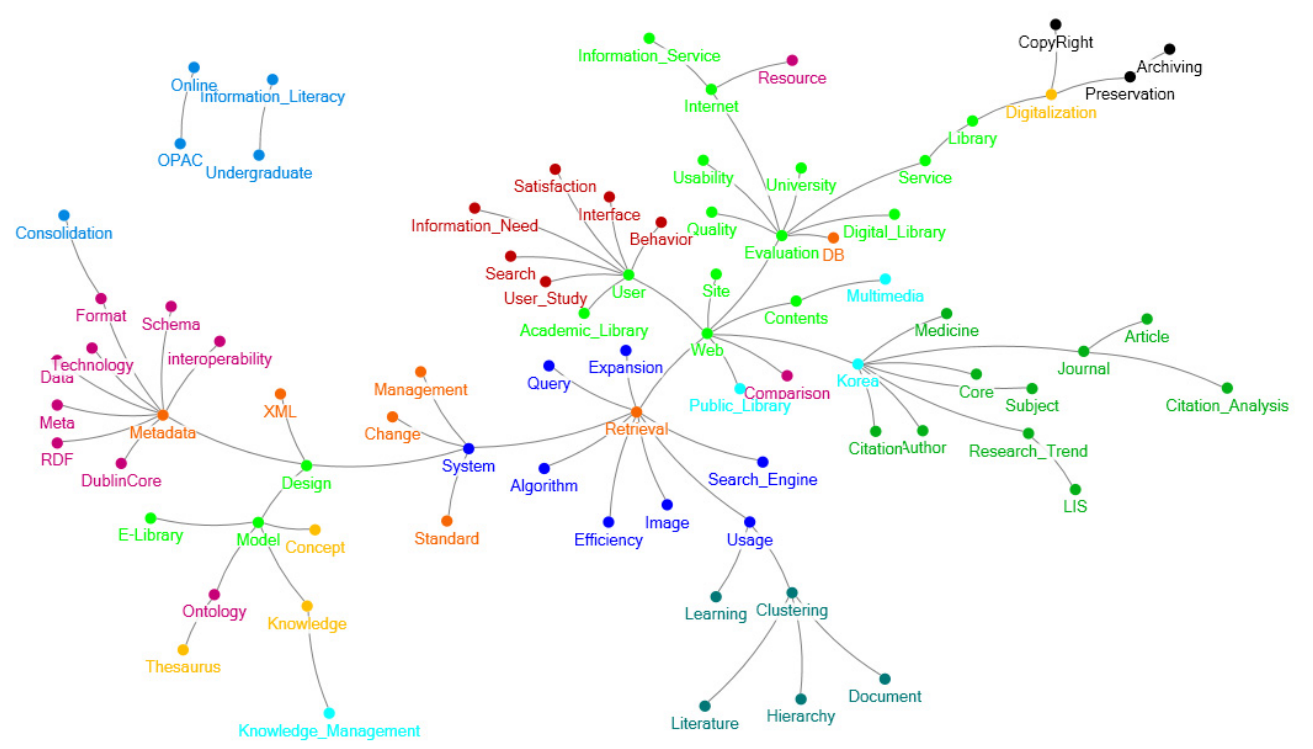

〈Figure 4〉Intellectual Structure of Information Science in Korea, 2000-2005

〈Table 9〉 Research domains and pertinent keywords in 2000-2005

\begin{tabular}{l|l}
\hline \multicolumn{1}{c|}{ Specialty } & \multicolumn{1}{|c}{ Keywords } \\
\hline Library Services (17) & $\begin{array}{l}\text { Contents, Design, Library, User, University, Academic Library, Digital Library, Model, Usability, } \\
\text { Site, Service, Web, Internet, E-Library, Information Service, Evaluation, Quality }\end{array}$ \\
\hline $\begin{array}{l}\text { Information Organization } \\
\text { (11) }\end{array}$ & $\begin{array}{l}\text { Format, RDF, Technology, Dublin Core, Data, Meta, Comparison, interoperability, Schema, } \\
\text { Ontology, Resource }\end{array}$ \\
\hline Informetrics (10) & Article, LIS, Research Trend, Medicine, Citation, Citation Analysis, Author, Subject, Journal, Core \\
\hline IR (8) & Efficiency, Search Engine, System, Algorithm, Image, Usage, Query, Expansion \\
\hline $\begin{array}{l}\text { Information System } \\
\text { Management (7) }\end{array}$ & XML, Retrieval, Management, DB, Metadata, Change, Standard \\
\hline Use \& Users (6) & Behavior, Satisfaction, User Study, Interface, Information Need, Search \\
\hline Text Mining (5) & Hierarchy, Literature, Document, Clustering, Learning \\
\hline Library Application (4) & Public Library, Multimedia, Knowledge Management, Korea \\
\hline Basic Concept (4) & Concept, Digitalization, Thesaurus, Knowledge \\
\hline Information Issue (3) & Preservation, Archiving, Copyright \\
\hline General (5) & Information Literacy, OPAC, Undergraduate, Online, Consolidation \\
\hline
\end{tabular}


clusters. 'IR' which is composed of 8 terms is connected to other specialty, such as 'Text Mining.' However, it is surprising that ' $I R$ ' builds a relatively small cluster, compared to other studies which revealed the 'Information Retrieval' specialty as the largest and main cluster (White \& McCain 1998; Zhao \& Strotmann 2008). 'Use \& Users' composed of 6 terms strongly connects with 'Library Services' composed of 17 terms via the term of 'user.' It evidently supports that IS researchers focused on evaluation of the Web environment changes in library services by conducting user studies. 'Informetrics' cluster which is a component of 'citation', 'journal', 'research trends', and 'literature' indicated that analyses on research activities and journals publication have been studied actively at that time. 'Information Organization' specialty located on the left end and its 11 terms are loosely connected to each other via the keywords of 'metadata.' Therefore, it can be concluded that studies in retrieval, user studies and library services were the core areas, and that in Korea, in the 20002005 period, the trend of IS studies expanded from Web-based system oriented to applications in library system and information organization.

$<$ Figure $5>$ presents the IS structure of the second period with 114 keyword terms which co-occurred in more than 3 papers; this structure suggests a somewhat different picture. Some changes in keywords indicate that the focus of the recognized specialties shifted, as well. First of all, 10 components are identified by PCA and they are differentiated by the color of corresponding keyword nodes. Comparing to the previous time window, it is found that specification of 'Library Services' by shrinking the size of 'Library Services' down and emerging new specialties, such as 'Library System', or 'Digital Library.'

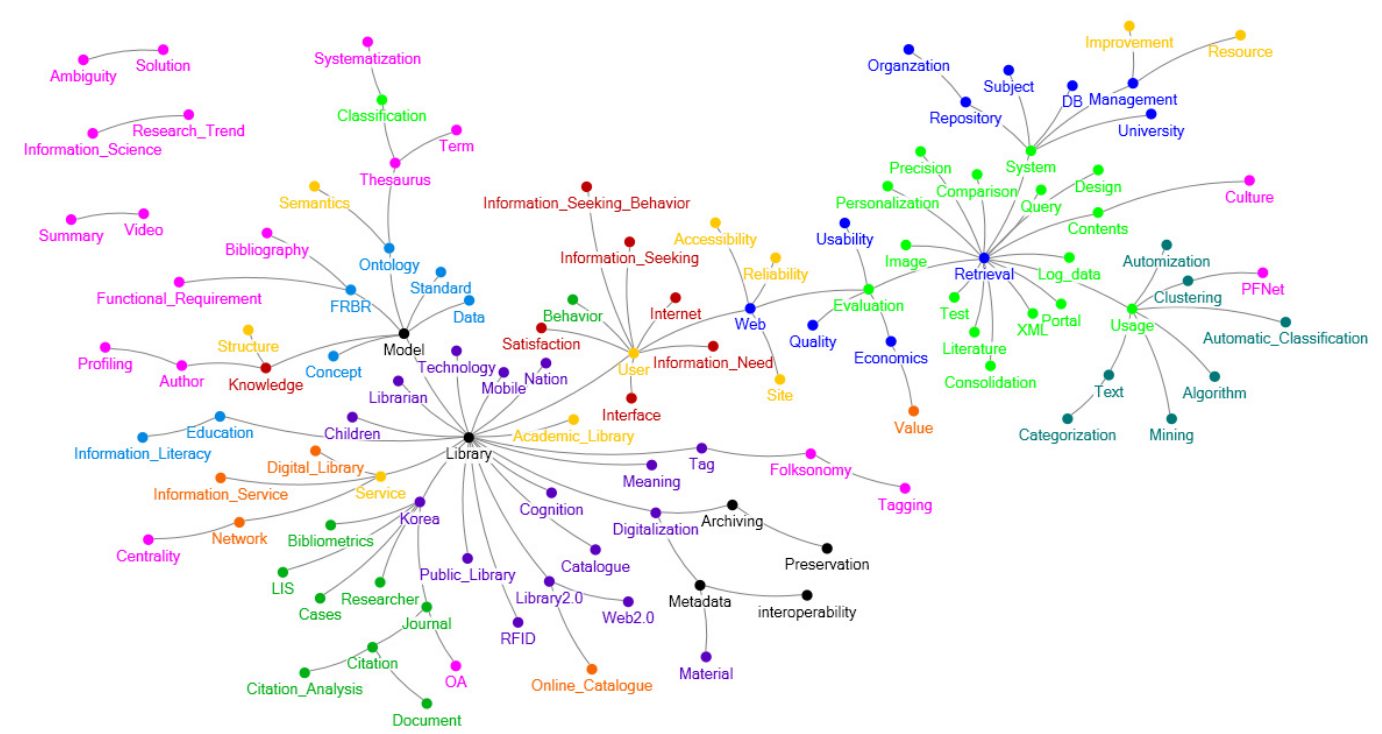

〈Figure 5〉Intellectual Structure of Information Science in Korea, 2006-2011 
$\langle$ Table 10〉 Research domains and pertinent keywords in 2006-2011

\begin{tabular}{l|l}
\hline \multicolumn{1}{c|}{ Specialty } & \multicolumn{1}{c}{ Keywords } \\
\hline $\begin{array}{l}\text { Information System Application } \\
\text { (17) }\end{array}$ & $\begin{array}{l}\text { Contents, Design, XML, Personalization, Log data, Literature, Classification, Comparison, } \\
\text { System, Test, Image, Usage, Precision, Query, Consolidation, Evaluation, Portal }\end{array}$ \\
\hline Library \& Web 2.0 (16) & $\begin{array}{l}\text { RFID, Public Library, Nation, Technology, Library2.0, Digitalization, Mobile, } \\
\text { Catalogue, Librarian, Children, Web2.0, Meaning, Cognition, Material, Tag, Korea }\end{array}$ \\
\hline $\begin{array}{l}\text { Information System } \\
\text { Management (11) }\end{array}$ & $\begin{array}{l}\text { Economics, Retrieval, Management, Organization, University, DB, Repository, Usability, } \\
\text { Web, Subject, Quality }\end{array}$ \\
\hline Library Services (10) & $\begin{array}{l}\text { User, Improvement, Structure, Academic Library, Site, Service, Semantics, Reliability, } \\
\text { Resource, Accessibility }\end{array}$ \\
\hline Informetrics (9) & $\begin{array}{l}\text { Behavior, Bibliometrics, Document, LIS, Researcher, Citation, Citation Analysis, Journal, } \\
\text { Cases }\end{array}$ \\
\hline Text Mining (7) & $\begin{array}{l}\text { Mining, Categorization, Algorithm, Automization, Automatic Classification, Clustering, } \\
\text { Text }\end{array}$ \\
\hline Use \& Users (7) & $\begin{array}{l}\text { Satisfaction, Internet, Interface, Information Need, Information Seeking, Information } \\
\text { Seeking Behavior, Knowledge }\end{array}$ \\
\hline Library System (7) & FRBR, Information Literacy, Concept, Education, Data, Ontology, Standard \\
\hline Info Issue (6) & Library, Metadata, Model, Preservation, interoperability, Archiving \\
\hline Digital Library (5) & Value, Network, Digital Library, Online Catalogue, Information Service \\
\hline General (19) & $\begin{array}{l}\text { Functional Requirement, Culture, Video, Bibliography, Thesaurus, Research Trend, OA, } \\
\text { Summary, Term, Author, Information Science, Centrality, Ambiguity, Systematization, } \\
\text { Tagging, PFNet, Folksonomy, Profiling, Solution }\end{array}$ \\
\hline
\end{tabular}

As the name of the components demonstrate, some clusters of the IS field were placed visibly apart, so that the number of keywords co-occurring with 'evaluation' or 'Web' shrank, and the word 'system' was not located in the main stem of the structure anymore. Instead, 'system' was moved and developed as a leaf keyword of 'retrieval', while 'user' was moved to the main stem with 'Web.' This result implies that the research interest on users and user studies was more directly connected to the evaluation of Web-based system.

Along with this, we can find that some components were more developed and expanded by merging another research topic with them. One of the visibly developed components was Information System
Management.' It had been a relatively small component in the previous period, but it may be noted that 'retrieval', 'usability', or 'system', and that it expanded related topics to the 'Information System Application', while 'retrieval' had been connected to both the system and evaluation in the previous period. Unlike in the previous period, the word of 'evaluation' was loaded to 'Information System Application', and 'evaluation', 'system', and 'use' were not connected to any keywords of the same category directly: ‘quality' and 'usability' connected with 'evaluation'; 'site', 'reliability', and 'accessibility' linked to the 'Web'; and 'interface', 'satisfaction', 'behavior' and 'information need' connected with 'user.' 
Surprisingly, the significant advance in research activities in Korea in 2006-2011 led to the appearance of 'Library \& Web 2.0' specialty related to the keyword 'library' which was moved to main stem of the structure. The word of 'library' was co-occurred with 'education', 'services', 'library 2.0', 'digitalization', 'metadata', or 'digital library', etc., which comprised all practical issues in library and information services. This word was also directly connected with the keywords related to 'Informetrics' or 'Library Services.' These three components were all related to the applications of information science in library services. The cluster of 'Informetrics' was related to support researchers in terms of analyzing research trends and developing collections. To sum up, it can be concluded that the IS-application research, such as information services or information retrieval, has been noticeably increasing and enough to make a cluster, while the Web-oriented evaluation or system-related research have been decreasing.

\section{Conclusion}

Information Science is a field that emerged in the aftermath of the Second World War along with a number of new fields such as computer science. Now, Information Science has matured to the stage where even the study of its history has become a legitimate topic of research and has expanded to other disciplines (Tsay \& Shu, 2010). This study presented the distribution of research articles over the full range of subject areas in Information Science over a 12 - year period and analyzed its changes within intellectual structures in two 6-year periods. As a result, this study identified that there were some localized research trends of Information Science area in Korea within the 12- year period (2000-2011).

First of all, the research of the application of information science on library services, such as informetrics and knowledge discovery including metadata, was rapidly increasing in Korean scholarly community, while Internet-based or system-based research was decreasing over time. This result implies that Korean studies in information science were seeking localization and application of the domain to local information system and services, such as digital library and mining system (knowledge discovery, library services), classification and categorization (metadata), or reference service and collection development (informetrics and knowledge discovery). The subject areas identified within this big picture had a more supportive analysis results in terms of research productivity that showed an increasing number of articles published in specific subject categories, such as 'Informetrics', 'Information Organization', 'Information Retrieval', and 'Information Use \& Users', while the subject categories of Information System Design \& Evaluation', and 'Information System Application' showed a decreasing productivity rate. This finding was also supported by the analysis result at the sub-category level. 'Bibliometrics (Informetrics)' had an ascending trendline of publications, followed by 'research trends', 'information flow', 'ontology', 'HCI', 'metadata', 'multimedia retrieval', 'social network', 'automatic classification', and 'theories.' On 
the contrary, sub-subject areas with the highly decreased rate were 'information center', 'information services', 'legal issues', 'ERM', 'digitalization', 'DB evaluation', 'system design', 'IR model', and 'IR evaluation.' In more specific terms, 'data mining' grew most significantly in terms of the number of publications per year, followed by 'information theory', 'SNS', 'bibliometrics', 'query processing', 'ontology', 'trends analysis', 'interface design', and 'information literacy.' Along with the changes regarding subjects, there were also changes regarding keywords frequency in the domain. The occurrences of 'Internet' and 'technology' decreased sharply over the years, but those of 'services', 'metadata', 'evaluation', 'management', and 'library' incresed.

In the revealed knowledge map with co-words for the 2000-2011 period, it has been found that the specific knowledge domain went through changes over time. In the overall period, the 'Library Services' was located in the center of the structure, and it was connecting the five major areas such as Library \& Web 2.0', 'Information System Application', 'Information Organization \& Metadata', 'Informetrics', and 'Use \& Users.' Looking at the results of the study, or more precisely, comparing the maps of the two different time spans revealed that there are big changes in major areas in the knowledge structure. In the second period, it is found that 'Library Service' domain was developed by identifying several related specialties, such as, 'Library System' and 'Digital Library.' This diversity was also supported by the changes in co-wording pattern: the co-occurring keywords of 'evaluation' or 'Web' shrank down, and the word 'system' was moved and developed as a leaf keyword of 'retrieval.' Along with this, 'user' was moved to the main stem with 'Web.' The map of the first period, on the contrary, showed more complicatedly divided structures, with 'Library Services' located in the center and connected to Information Retrieval', 'Use \& Users', and 'Informetrics.' It was concluded that major publications of IS research in Korea were increasing in the domain of 'Informetrics' with specifying 'Library Services' into several related specialties regarding 'Use \& Users.' Also, it was found that the coverage of research area was expanding from Korea to the world scholarly community.

Comparing to other studies, this study emphasize the analysis of the dataset from KCI, regional citation index, in order to detect the localization pattern of information science studies in Korea. Furthermore, the follow-up analysis with longer publication windows compared with the results of the previous analysis could enrich the findings on IS research trends in Korea. To know where the discipline is going and where it has been is important to scholars and practitioners because it helps them understand knowledge of fundamental bases and emergent issues in the field. Therefore, drawing IS research areas or tracing its research trends is one way to understand and capture the knowledge of Information Science. 


\section{References}

Chu, C., \& Wolfram, D. (1991). A survey of the growth of Canadian research in information science. Canadian Journal of Information Science, 16(1), 12-28.

Chua, A. Y. K., \& Yang, C. C. (2008). The shift towards multi-disciplinarity in information science. Journal of the American Society for Information Science and Technology, 59(13), 2156-2170. http://dx.doi.org/10.1002/asi.20929

Cho, J. (2011). A study for research area of library and information science by network text analysis. Journal of the Korean Society for Information Management, 28(4), 65-83. http://dx.doi.org/10.3743/KOSIM.2011.28.4.065

Hansen, D., Shneiderman, B., \& Smith, M. A. (2010). Analyzing social media networks with NodeXL: Insights from a connected world. Morgan Kaufmann.

Hawkins, D. T. (2001). Information Science Abstracts: Tracking the literature of information science. Part 1: Definition and map. Journal of the American Society for Information Science, 52(1), 44-53.

Huang, M.-H., \& Chang, Y.-W. (2011). A study of interdisciplinarity in information science: Using direct citation and co-authorship analysis. Journal of Information Science, 37(4), 369-378. http://dx.doi.org/10.1177/0165551511407141

Kang, S.-S. (2002). Korean morphemes analysis and information retrieval. Seoul: Hong-Rung Scientific Pub.

Kim, P. J., \& Lee, J. Y. (2007). Descriptor profiling for research domain analysis. Journal of the Korean Society for Information Management, 24(4), 285-303. http://dx.doi.org/10.3743/KOSIM.2007.24.4.285

Lee, J. Y., \& Choi, S. (2011). Intellectual structure and infrastructure of informetrics: Domain analysis from 2001 to 2010. Journal of the Korean Society for information Management, 28(2), 11-36. http://dx.doi.org/10.3743/KOSIM.2011.28.2.011

Lee, J. Y., Kim, P. J., Kang, D. S., Kim, H. J., Yu, S. Y., \& Lee, W. H. (2011). A bibliometric analysis on LED research. Journal of Information Management, 42(3), 1-26.

http://dx.doi.org/10.1633/JIM.2011.42.3.001

Mukherjee, B. (2010). Assessing Asian scholarly research in library and information science: A quantitative view as reflected in Web of Knowledge. Journal of Academic Librarianship, 36(1), 90-101. http://dx.doi.org/10.1016/j.acalib.2009.12.003

NWB Team (2006). Network Workbench Tool. Indiana University, Northeastern University, and University of Michigan. Retrieved from http://nwb.slis.indiana.edu

Oh, S.-H., \& Lee, D.-Y. (2005). Research trends of information science in Korea. Journal of Korean Society of Information Management, 22(1), 167-189. http://dx.doi.org/10.3743/KOSIM.2005.22.1.167 
Park, J.-H., \& Song, M. (2013). A study on the research trends in library \& information science in Korea using topic modeling. Journal of the Korean Society for Information Management, 30(1), 7-32. http://dx.doi.org/10.3743/KOSIM.2013.30.1.007

Robinson, L. (2009). Information science: Communication chain and domain analysis. Journal of Documentation, 65(4), 578-591. http://dx.doi.org/10.1108/00220410910970267

Rorissa, A., \& Yuan, X. (2012). Visualizing and mapping the intellectual structure of information retrieval. Information Processing and Management, 48(1), 120-135. http://dx.doi.org/10.1016/j.ipm.2011.03.004

Schvaneveldt, R. W. (Ed.) (1990). Pathfinder associative networks: Studies in knowledge organization. Norwood, NJ: Ablex.

Seadle, M. (2012). Library Hi Tech and information science. Library Hi Tech, 30(2), 205-209. http://dx.doi.org/10.1108/07378831211239915

Seo, E.-G. (1997). An analytical study on research patterns in information science. Journal of Korean Society of Information Management, 14(1), 269-291.

Seo, E.-G. (2010a). Longitudinal analysis of information science research in JASIST 1985-2009. Journal of Korean Society of Information Management, 27(2), 129-155. http://dx.doi.org/10.3743/KOSIM.2010.27.2.129

Seo, E.-G. (2010b). Trends analysis on research articles in the Journal of Korean Society for Information Management. Journal of Korean Society of Information Management, 27(4), 7-32. http://dx.doi.org/10.3743/KOSIM.27.4.007

Sohn, J.-P. (2003). An analytical study on research trends of library and information science in Korea: 1957 2002. Journal of Korean Library and Information Science Society, 34(3), 9-32.

Tsay, M.-y., \& Shu, Z.-y. (2010). Journal of bibliometric analysis: The case study on the Journal of Documentation. Journal of Documentation, 67(5), 806-822. http://dx.doi.org/10.1108/00220411111164682

White, H. D., \& McCain, K. W. (1998). Visualizing a discipline: An author co-citation analysis of information science, 1972-1995. Journal of the American Society for Information Science, 49(4), 327-355.

Wolfram, D. (2012). An analysis of Canadian contributions to the information science research literature: 1989-2008. Canadian Journal of Information and Library Science, 36(1-2), 52-66. http://dx.doi.org/10.1353/ils.2012.0005

Zhao, D., \& Stromann, A. (2008). Information science during the first decade of the web: An enriched author co-citation analysis. Journal of the American Society for Information Science and Technology, 59(6), 916-937. http://dx.doi.org/10.1002/asi.v59:6

Zins, C. (2007). Knowledge map of information science. Journal of the American Society for Information Science and Technology, 58(4), 524-535. http://dx.doi.org/ 10.1002/asi.20505 